\title{
BMJ A cross-sectional study to identify Open organisational processes associated with nurse-reported quality and patient safety
}

\author{
Christine Tvedt, ${ }^{1,2}$ Ingeborg Strømseng Sjetne, ${ }^{1}$ Jon Helgeland, ${ }^{1}$ Geir Bukholm ${ }^{2,3}$
}

To cite: Tvedt C, Sjetne IS, Helgeland J, et al. A crosssectional study to identify organisational processes associated with nurse-reported quality and patient safety. BMJ Open 2012;2:e001967. doi:10.1136/bmjopen-2012001967

- Prepublication history for this paper are available online. To view these files please visit the journal online (http://dx.doi.org/10.1136/ bmjopen-2012-001967).

Received 16 August 2012 Revised 16 November 2012 Accepted 19 November 2012

This final article is available for use under the terms of the Creative Commons Attribution Non-Commercial 2.0 Licence; see http://bmjopen.bmj.com

\footnotetext{
${ }^{1}$ Department of Quality Measurement and Patient Safety, The Norwegian Knowledge Centre for the Health Services, Oslo, Norway

${ }^{2}$ Institute of Health and Society, University of Oslo, Oslo, Norway ${ }^{3}$ Centre for Laboratory Medicine, Østfold Hospital Trust, Fredrikstad, Norway
}

Correspondence to Christine Tvedt; cht@nokc.no

\author{
ABSTRACT \\ Objectives: The purpose of this study was to identify \\ organisational processes and structures that are \\ associated with nurse-reported patient safety and \\ quality of nursing.
}

Design: This is an observational cross-sectional study using survey methods.

Setting: Respondents from 31 Norwegian hospitals with more than 85 beds were included in the survey.

Participants: All registered nurses working in direct patient care in a position of $20 \%$ or more were invited to answer the survey. In this study, 3618 nurses from surgical and medical wards responded (response rate 58.9). Nurses' practice environment was defined as organisational processes and measured by the Nursing Work Index Revised and items from Hospital Survey on Patient Safety Culture.

Outcome measures: Nurses' assessments of patient safety, quality of nursing, confidence in how their patients manage after discharge and frequency of adverse events were used as outcome measures.

Results: Quality system, nurse-physician relation, patient safety management and staff adequacy were process measures associated with nurse-reported work-related and patient-related outcomes, but we found no associations with nurse participation, education and career and ward leadership. Most organisational structures were non-significant in the multilevel model except for nurses' affiliations to medical department and hospital type.

Conclusions: Organisational structures may have minor impact on how nurses perceive work-related and patient-related outcomes, but the findings in this study indicate that there is a considerable potential to address organisational design in improvement of patient safety and quality of care.

\section{INTRODUCTION}

The report 'Crossing the quality chasm' from the Institute of Medicine in 2001 called for a system change to improve safety in the healthcare services. ${ }^{1}$ The report led to establishment of patient safety programmes and healthcare reforms in many Western countries. The introduction of evidence-

\section{ARTICLE SUMMARY}

Article focus

- Identifying organisational processes and structures associated to nurse-reported quality and patient safety in hospitals.

- Increase knowledge about organisational design promoting patient safety among nurses as a microsystem of hospitals.

Key message

- Addressing organisational design may have a considerable potential to improve patient safety and quality of care.

Strengths and limitations of this study

- A considerable number of nurses have given their responses on a multicentre nurse survey providing a valuable data material.

- Several aspects of the survey method may have influenced the results of this study.

based practice, guidelines, performance measurements and feedback has characterised patient safety initiatives in hospitals during the last decade. Results from evaluations of the interventional efforts are inconsistent, and several authors have described a need to better understand how organisational features contribute to quality and patient safety in hospitals. ${ }^{2-4}$ The organisational climate is defined by the employees' perceptions of these features, and might be understood as structural properties of the organisation and the organisational work environment. ${ }^{5}$ Both organisational structures (eg, hospital size and hospital volume) and organisational processes (eg, patient safety climate and perception of work environment) have been associated with safety outcomes. ${ }^{4-6}$

The system perspective is based on how input to the healthcare system is managed and how this input benefits the patients and society. $^{1}$ Donabedian's model for quality serve as a framework to understand how hospital structures and processes contribute to healthcare outcomes and the model is 
modified by Battles et al to illustrate how processes exist within the structure of the healthcare system. ${ }^{7-9}$ Battles describes how adjustments of organisational structures and processes may contribute to a reduction of failures that cause adverse events. An organisational climate where processes and structures allow patient safety improvements is required to minimise the failures of care. $^{3}{ }^{9}$ Inertia of organisational change observed in healthcare institutions is suggested as one explanation for why the "progress of patient safety improvements has been slow'. ${ }^{3}$ A leadership with clear visions and strategies is a key to transformational change towards a patient safe organisation, and knowledge about how healthcare workers assess their work environment and patient safety in their work place should therefore be essential to these leaders. ${ }^{10}$

The growing body of evidence on how work environment is associated with healthcare performance support this view. In studies of physicians' work environment associations with the quality of health service delivery have been presented and improvement of nurses' work environment is suggested as a cost-effective strategy to improve patient outcomes. ${ }^{11-15}$ Several studies have presented associations between nurses' work environment and patient outcomes like adverse events, risk-adjusted mortality and patient satisfaction. ${ }^{15-21}$ These are important studies identifying associations between patient outcome and features of the healthcare organisation. However, the way healthcare workers perceive and report patient safety serve as essential information to investigate how processes and structures support patient safe healthcare organisations. ${ }^{9} 2223$

A few studies emphasise the differences in how professions perceive patient safety, and it may be useful to understand the attitudes and perceptions towards patient safety within professions. ${ }^{22}$ 24-27 The planning and implementation of strategies and interventions to improve patient safety may also take such variations into account. Despite the fact that nurse-reported quality of care have been associated with failure to rescue, patient satisfaction and processes of care, a small number of studies have explored how nurse-reported patient safety is associated with work environment. ${ }^{28-33}$

\section{OBJECTIVES}

Nurses constitute a large proportion of healthcare workers, and how they perceive an organisational design promoting patient safety is essential information about nurses as a microsystem. ${ }^{4} 84$ The purpose of this study was to identify organisational process measures in nurses' work environment and hospital characteristics (organisational structure measures) that were associated with nurse-reported patient safety and quality of nursing. In particular, we were interested in which process measures remained after adjusting for organisational structure measures.

\section{METHODS}

\section{Design}

The theoretical approach of this observational crosssectional study was based on Donabedian's dimensions of a quality model: structure, process and outcome. We modified Battles' version of this model to illustrate how we applied hospital characteristics, nurses' work environment and nurse-reported quality of nursing and patient safety to the model (figure 1). The readers should bear in mind that these variables only represent part of a complex reality.

\section{Data collection}

This study involved a survey among nurses in surgical and medical wards in 35 Norwegian hospitals with more than 85 beds. Data collection was part of the European RN4 Cast study. ${ }^{11}$ A paper questionnaire, information letter, and return envelope were distributed through the nurses' union representatives to 9548 nurses during the autumn of 2009. Registered nurses working in direct patient care in a position of $20 \%$ or more were included, and nurses on long-term leaves were excluded. Nurses received the questionnaire at their workplaces, and the distribution procedures included collection of information about nurses' affiliations to hospital, department and ward. Personal reminders were not distributed as the respondents' names and addresses were not available to the researchers. In some hospital wards the union representatives and/or nurse leaders gave collective reminders. The method of data collection and handling was approved by the Data Protection Official for Research.

\section{Nurse-reported outcome measures}

The use of self-reported outcomes in this study was necessary to describe how nurses perceived quality of nursing and patient safety at their work places. Single-item overall assessment of quality of nursing and patient safety were used as outcome variables as practiced in other studies investigating nurse-reported quality and patient safety. ${ }^{30-33} 35$ We defined four items as variables that describe how nurses report work performance; 'work-related measures', and how nurses describe patient outcomes, 'patient-related measures'.

\section{Work-related outcome measures}

- Quality of nursing: In general, how would you describe the quality of nursing care delivered to patients on your unit/ward? (four-point Likert-type scale where $1=$ poor, $2=$ fair, $3=$ good and $5=$ excellent, meaning that high scores indicate better quality).

- Patient safety: Please give your department an overall grade on patient safety. (Five-point Likert-type scale where $1=$ failing, $2=$ poor, $3=$ acceptable, $4=$ very good and $5=$ excellent, meaning that high scores indicate better patient safety). 


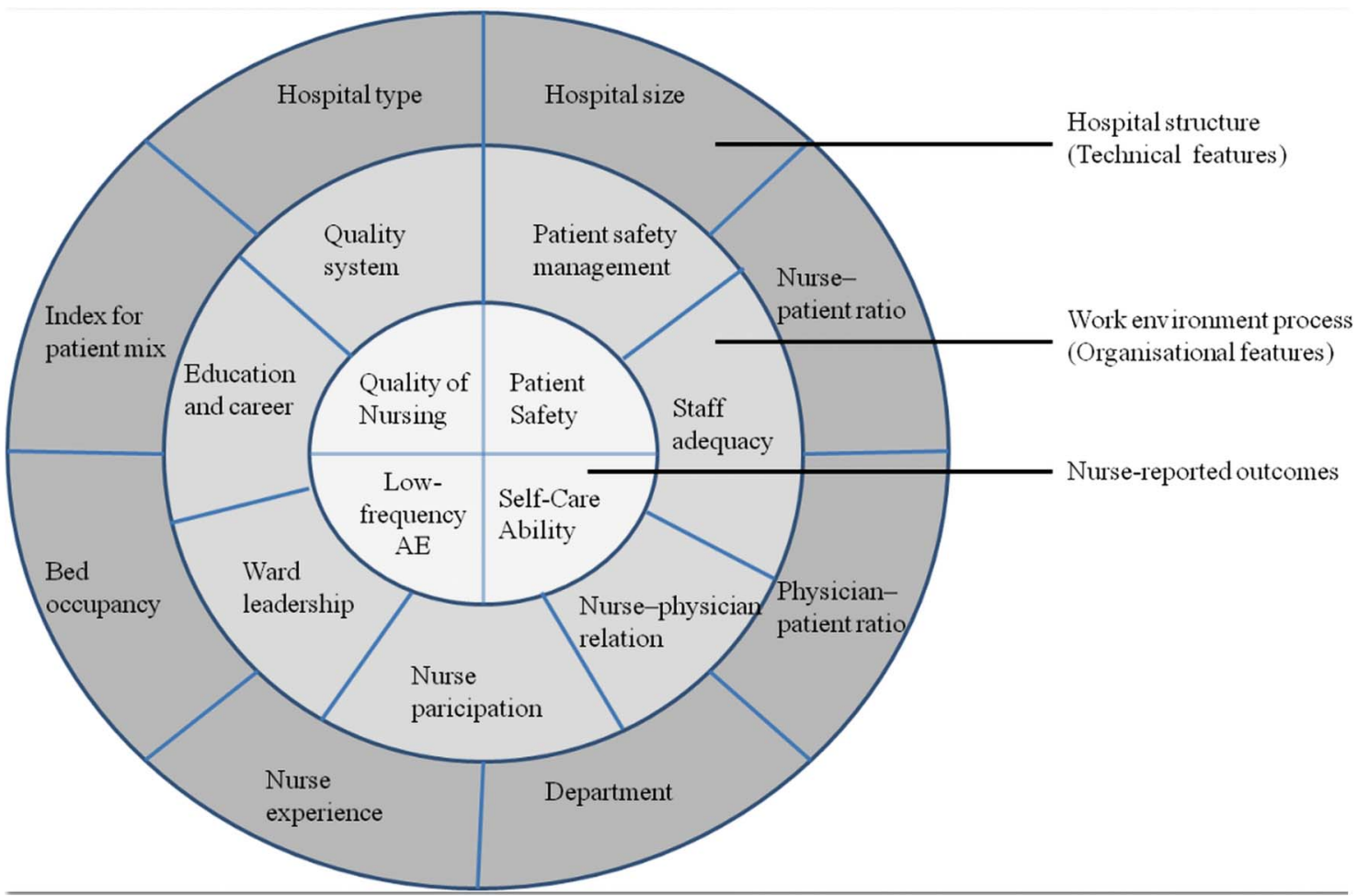

Figure 1 Modification of Battles' model to illustrate the understanding of structure, process and outcome in this context. ${ }^{7}$ $A E$, adverse events (low frequency of adverse events).

\section{Patient-related outcome measures}

- Self-care ability: How confident are you that your patients are able to manage their care when discharged? (Four-point Likert-type scale where $1=$ not at all confident, 2=somewhat confident, 3=confident and $4=$ very confident, meaning that high scores indicate more confidence in how patients manage).

- Low frequency of adverse events (AE): Nurses were also asked to estimate how frequently adverse events have happened to their patients on a seven-point Likert-type scale (1=never, $2=$ some times per year, $3=$ once a month or less, $4=$ some times per month, $5=$ once a week, $6=$ some times per week and $7=$ every day). We recoded the subscale into the opposite direction so that the lowest frequency was given the highest score (low frequency AE=preferably).

Different types of adverse events were subjects of the question and in this study we calculated the mean of the seven adverse events scores per nurse

- Pressure ulcers after admission;

- Patients received wrong medication, time or dose;

- Patient falls with injury;

- Urinary tract infections;

- Bloodstream infections;

- Complaints from patients or their families and

- Pneumonia.

\section{Organisational process measures}

Nurses' work environment was measured by the instrument Nursing Work Index $(\mathrm{NWI})^{36}$ and a subscale including items from The Hospital Survey on Patient Safety Culture (HSOPSC). ${ }^{37}$ These variables were regarded as organisational processes and made the following variables:

- Education and career;

- Nurse participation;

- Quality system;

- Ward leadership;

- Staff adequacy;

- Nurse physician relation and

- Patient safety management.

The Norwegian version of NWI was translated and tested according to acknowledged procedures for questionnaire modifications between cultures. ${ }^{38}$ We performed an exploratory factor analysis to identify the factor structure of the Norwegian dataset. The subscales identified were used as explanatory variables in the study.

The items were four-point Likert-type scales, and high scores indicated agreement that the features were present in the job situation ( $1=$ strongly disagree, $2=$ somewhat disagree, $3=$ =somewhat agree and $4=$ strongly agree). The scale scores were noted as missing if more than $50 \%$ of scores in the single items were missing.

Leadership is essential for the development of organisational/patient safety culture. ${ }^{37} 3940$ Three items from the HSOPSC-questionnaire represented leadership topics such as performance feedback and actions showing that patient safety have priority in hospital management. We regarded a subscale of these items as process measure for the work environment. High scores 
indicated agreement that the items were present in the job situation (five-point Likert-type scale: $1=$ strongly disagree, $2=$ disagree, $3=$ neither, $4=$ agree and $5=$ strongly agree).

\section{Organisational structure measures}

Information about the hospitals were collected from public registers, reported from hospital administrators on our request or aggregated from the survey data. ${ }^{41} 42$ The following measures were used as organisational structure variables:

- Nurse-patient ratio (number of nurse man-years per 10000 patient days, 2009) ${ }^{42}$

- Physician-patient ratio (number of physician man-years per 10000 patient days, 2009) ${ }^{42}$

- Index for patient mix (the ratio between the number of DRG-points and the number of admissions, 2009) ${ }^{41}$

- Hospital size (number of beds, 2009) ${ }^{41}$

- Hospital type (made as two dummy-variables):

- Regional university hospital (reference value: local hospital)

- Local university hospital (reference value: local hospital)

- Bed occupancy (mean bed occupancy in percent for 2009, hospital reported)

- Medical department (from the nurse survey: Nurses' affiliation to medical department with reference value: surgical department)

- Nurse experience (in years per hospital derived from survey data)

Regional university hospitals were defined as university hospitals with national responsibilities, while local university hospitals were defined as university hospitals without national responsibilities. All other hospitals were defined as 'local hospitals'. We collected organisational structure measures to ensure validity and comparability for all hospitals included in the survey. The measures selected for this study was chosen after considerations of literature discussing the context of patient safety research and practices. Hospital type and size, patient clinical complexity and professional staffing are suggested as essential structural features. ${ }^{4} 643-45$

\section{STATISTICAL ANALYSIS}

All analyses were made using SPSS V.15.0.

We used exploratory factor analysis to examine the structure of NWI in the Norwegian dataset, including nurses working in intensive care units, medical and surgical wards $(\mathrm{n}=5490)$. We performed reliability tests to assess internal consistency for the NWI and for the subscale from HSOPSC.

The questionnaire was distributed to 6147 nurses in medical and surgical wards, and 3618 responded (mean response rate: $58.9 \%$ ). Based on recommendations for cut points for response rates we included 31 hospitals with a survey response rate above $40 \% .{ }^{46}$ Nurses from intensive care units were excluded because the number of these units, the size and the type of patients admitted vary between hospitals.

The values of all variables' were transformed into a 0 100 scale, 0 representing the lowest possible score and 100 the highest possible score. Organisational structure variables were transformed into variables relative to hospital type to control for the assumption of dependency with hospital type (in the following marked with ' $\mathrm{R}$ ' in variable names). The transformation was made by subtracting the mean values of hospital type for each case. The unit of observation was individuals. Descriptive statistics of organisational structure measures were made at hospital-aggregated level.

Initially bivariate regression analysis for each organisational variable and each nurse-reported outcome was performed. In the stepwise multivariate regression that followed, all organisational variables and all potential interactions were included. Main effects and interactions that remained significant on a 0.05 level were included in the final multivariate multilevel regression introducing hospital ward and hospital as levels 2 and 3 variables. Interactions between hospital type and other structural variables were removed in the final model because they were related to features of single hospitals.

\section{RESULTS}

The exploratory factor analysis identified six subscales from NWI, and internal consistency (Cronbach's $\alpha$ ) ranged from 0.68 to 0.88 in the reliability test (see table 1). A comparison of the subscales we identified and the subscales from PES-NWI $^{36}$ is presented in figure 2. Internal consistency (Cronbach's $\alpha$ ) of the three items from HSOPSC was 0.72.

The structural characteristics of hospitals are described in table 2. Most of the hospitals were categorised as local (23), but three hospitals were local university hospitals and another five were regional university hospitals.

About $90 \%$ of Norwegian nurses are members of The Norwegian Nurses Organisation (NNO). Mean age among the members of $\mathrm{NNO}$ are 43.0 , and $90 \%$ are female. The mean age of nurse respondents $(\mathrm{N}=3618)$ in this study was 35.6 (median 33.0, range 21-71), and their mean experience as nurses was 8.4 (median 5.0, range $0-45)$. Most nurses were female $(93.8 \%)$. All registered nurses in Norway hold a bachelor's degree, and $15.3 \%$ of the respondents had further education. The distribution of nurses between hospital types was 13.6\% for local university hospital and $29.2 \%$ for regional university hospital. The distribution between departments was about even, with $56.4 \%$ of nurses working in medical departments.

Organisational process variables are presented in table 3. Nurse participation and staff adequacy had the lowest scores, while nurse-physician relation and ward leadership had high scores.

Bivariate linear regression showed that, with a few exceptions, organisational structure and process 
Table 1 Internal consistency (Cronbach's $\alpha$ ) of subscales

\begin{tabular}{lll}
\hline Subscales & $\begin{array}{l}\text { Number of } \\
\text { items }\end{array}$ & $\begin{array}{l}\text { Internal consistency } \\
\text { (Cronbach's } \boldsymbol{\alpha})\end{array}$ \\
\hline $\begin{array}{l}\text { Staff adequacy } \\
\text { Nurse physician }\end{array}$ & 3 & 0.80 \\
relation & 7 & 0.88 \\
Ward leadership & 4 & 0.78 \\
$\begin{array}{l}\text { Nurse participation } \\
\text { Education and }\end{array}$ & 5 & 0.68 \\
career (possibilities) & 4 & 0.73 \\
$\begin{array}{l}\text { Quality system } \\
\text { Patient safety }\end{array}$ & 7 & 0.71 \\
management & 3 & 0.72 \\
\hline
\end{tabular}

measures were associated with nurses' reports of Quality of Nursing, Patient Safety, Self-Care Ability and Low frequency AE. The final multivariate multilevel model introducing hospital ward and hospital as levels 2 and 3 variables, showed that almost all variance was found on an individual level and demonstrated that correlation among observations within the hospitals was lower than for hospital wards (table 4 ). The correlation at hospital level accounted for $0.22-0.74 \%$ of the total variance, and correlation at hospital ward level accounted for 2.46-8.64\% of the total variance (table 4).

Intraclass correlation coefficients and design effects for each outcome are presented in table 4.
Table 2 Characteristics of the included hospitals $(\mathrm{N}=31)$

\begin{tabular}{|c|c|c|}
\hline Hospital characteristics & Median & $\begin{array}{l}\text { Minimum- } \\
\text { maximum }\end{array}$ \\
\hline Hospital size* & 414 & $85-$ \\
\hline dex for patient mix $†$ & 8.0 & $6.9-$ \\
\hline Physician-patient ratio & & $9.6-$ \\
\hline Nurse-patient ratio§ & 53.3 & $29.9-82.9$ \\
\hline $\begin{array}{l}\text { Nurse experience (number of } \\
\text { years per hospitalq }\end{array}$ & 8.6 & $4.1-13.3$ \\
\hline Bed occupancy ${ }^{\star *}$ & 87.3 & $75.2-102.7$ \\
\hline \multicolumn{3}{|c|}{$\begin{array}{l}\text { *Number of beds. } \\
\text { †The ratio between the number of DRG-points and the number of } \\
\text { admissions. } \\
\text { †Number of physician-years per } 10000 \text { patient day. } \\
\text { §Number of nurse-years per } 10000 \text { patient days. } \\
\text { १Mean years of experience among the respondents per hospital. } \\
{ }^{\star \star} \text { Per cent, bed occupancy for } 2009 \text {. }\end{array}$} \\
\hline
\end{tabular}

The multivariate multilevel model showed that nurses' reports of work-related outcome measures; Quality of Nursing, and Patient Safety, were associated with four of the organisational process measures; patient safety management, staff adequacy, nurse-physician relation and quality system (table 4). Small but significant coefficients were found for associations between Quality of Nursing and nurse participation (negative) and ward leadership (positive). Working at a regional university hospital rather than at a local hospital was associated with both work-

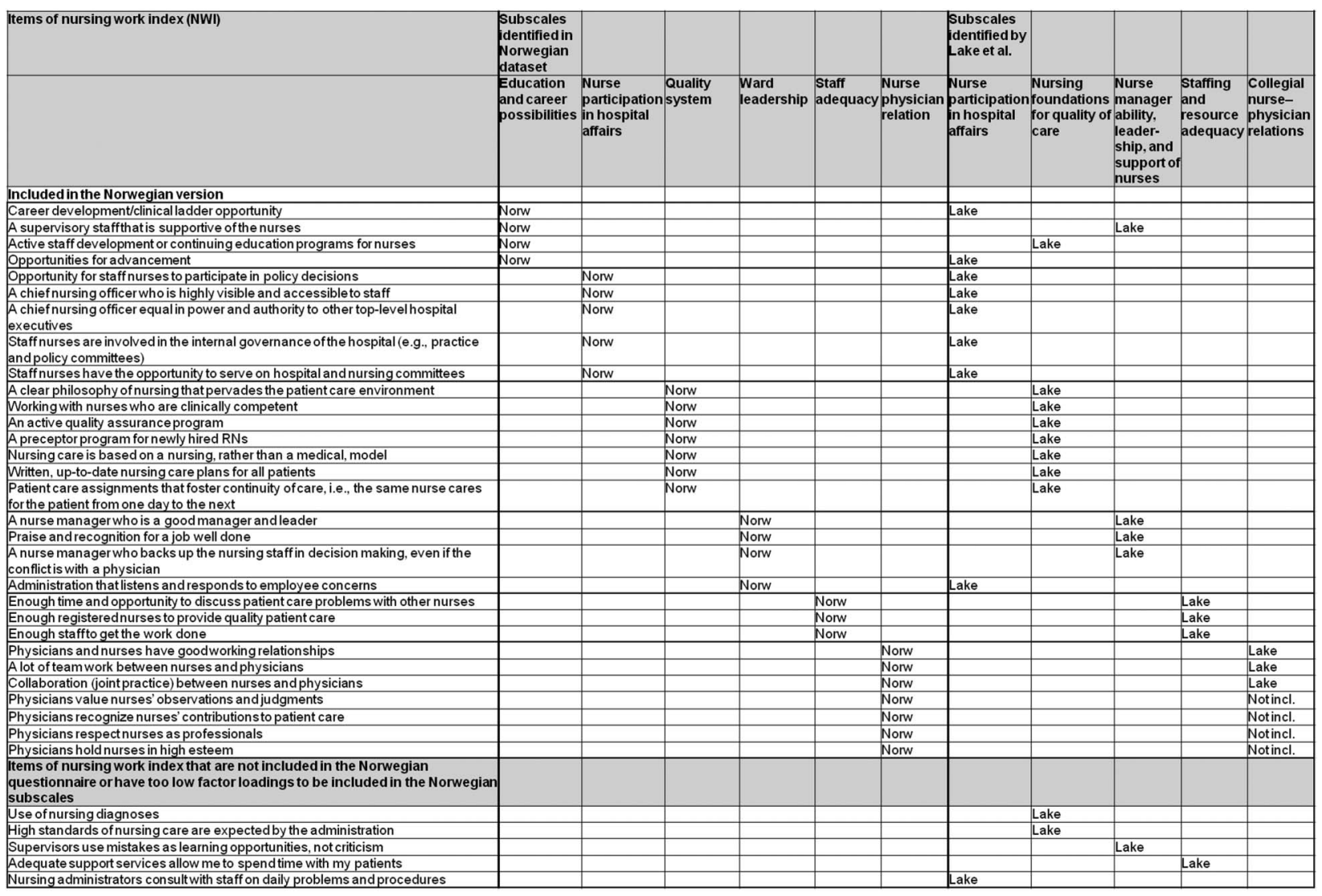

Figure 2 Comparison of PES-NWI and subscales identified from Norwegian data. 
Table 3 Nurses' assessment of organisational process measures $(\mathrm{N}=3618)$

\begin{tabular}{|c|c|c|c|c|}
\hline $\begin{array}{l}\text { Hospital } \\
\text { characteristics }\end{array}$ & $\mathbf{N}$ & Median & $\begin{array}{l}\text { Minimum- } \\
\text { maximum }\end{array}$ & SD \\
\hline $\begin{array}{l}\text { Patient safety } \\
\text { management }\end{array}$ & 3556 & 58.3 & $0-100$ & 18.7 \\
\hline Staff adequacy & 3602 & 44.4 & $0-100$ & 22.4 \\
\hline $\begin{array}{l}\text { Nurse-physician } \\
\text { relation }\end{array}$ & 3602 & 66.67 & $0-100$ & 15.9 \\
\hline $\begin{array}{l}\text { Education and } \\
\text { career }\end{array}$ & 3603 & 50.0 & $0-100$ & 20.5 \\
\hline Quality system & 3594 & 52.4 & $0-100$ & 15.8 \\
\hline Nurse participation & 3641 & 40.0 & $0-100$ & 17.6 \\
\hline Ward leadership & 3612 & 66.67 & $0-100$ & 20.6 \\
\hline
\end{tabular}

related outcome measures. Nurses affiliated to medical departments gave lower ratings of Patient Safety than nurses working in surgical departments.

The patient-related outcome measures, Self-Care Ability and Low frequency AE, were associated with the organisational process measures patient safety management, staff adequacy and quality system. Self-Care Ability was associated with nurse-physician relation (positively) and low frequency $\mathrm{AE}$ was associated with ward leadership (negatively). Nurses working in a medical department reported poorer Self-Care Ability. Nurses working a local university hospital rather than a local hospital reported higher frequency of adverse events (reduced low frequency $\mathrm{AE}$ ). The interactions included in the final model showed that index for patient mix reduced the negative effect of medical department on Self-Care Ability. High nurse experience per hospital increased the effect of nurse-patient ratio on Self-Care Ability. Except for medical department none of the main effects involved in the interactions were significant.

\section{DISCUSSION}

\section{Main findings}

Organisational process variables, quality system, patient safety management, staff adequacy and nurse-physician relation, were associated with nurse-reported work-related and patientrelated outcomes. The organisational structure variables medical department and hospital type were associated with some of the nurse-reported outcomes.

Table 4 Multivariate multilevel regression analysis of process/structure measures and nurses' self-reported work-related and patient-related outcomes $(\mathrm{N}=3618)$

\begin{tabular}{|c|c|c|c|c|}
\hline & \multicolumn{2}{|c|}{ Work-related outcomes } & \multicolumn{2}{|c|}{ Patient-related outcomes } \\
\hline & $\begin{array}{l}\text { Quality of } \\
\text { nursing }\end{array}$ & Patient safety & $\begin{array}{l}\text { Self-care } \\
\text { ability }\end{array}$ & $\begin{array}{l}\text { Low frequency } \\
A E\end{array}$ \\
\hline & \multicolumn{4}{|c|}{ Coefficient ( $p$ value) } \\
\hline \multicolumn{5}{|l|}{ Process measures } \\
\hline Patient safety management & $0.09(<0.001)$ & $0.19(<0.001)$ & $0.13(<0.001)$ & $0.06(<0.001)$ \\
\hline Staff adequacy & $0.12(<0.001)$ & $0.12(<0.001)$ & $0.10(<0.001)$ & $0.04(<0.001)$ \\
\hline Nurse-physician relation & $0.06(0.003)$ & $0.07(<0.001)$ & $0.08(0.006)$ & \\
\hline Education and career & & & & \\
\hline Quality system & $0.25(<0.001)$ & $0.18(<0.001)$ & $0.21(<0.001)$ & $0.09(<0.001)$ \\
\hline Nurse participation & $-0.04(0.028)$ & & & \\
\hline Ward leadership & $0.05(0.011)$ & & & $-0.03(0.008)$ \\
\hline \multicolumn{5}{|l|}{ Structure measures } \\
\hline Local university hospital & & & & $-3.08(0.008)$ \\
\hline Regional university hospital & $3.57(0.003)$ & $1.89(0.024)$ & $1.48(0.375)$ & \\
\hline Nurse-patient ratio-R & & & $0.21(0.127)$ & \\
\hline Physician-patient ratio-R & & & $-0.28(0.290)$ & \\
\hline Bed occupancy-R & & $0.00(0.955)$ & $-0.25(0.055)$ & $-0.09(0.127)$ \\
\hline Index for patient mix-R & $0.01(0.861)$ & & $0.10(0.415)$ & \\
\hline Nurse experience-R & & & $-0.77(0.071)$ & $0.33(0.051)$ \\
\hline Hospital size-R & & & $-0.02(0.533)$ & \\
\hline Medical department & $0.23(0.769)$ & $-1.12(0.039)$ & $-5.89(<0.001)$ & \\
\hline \multicolumn{5}{|l|}{ Interactions } \\
\hline $\begin{array}{l}\text { Index for patient mix-R } \times \text { Medical } \\
\text { department }\end{array}$ & $0.14(0.114)$ & & $-0.28(0.032)$ & \\
\hline Nurse-patient ratio- $R \times$ nurse experience- $R$ & & & $0.16(0.013)$ & \\
\hline Physician-patient ratio- $R \times$ nurse & & & $-0.28(0.066)$ & \\
\hline \multicolumn{5}{|l|}{ experience- $\mathrm{R}$} \\
\hline Bed occupancy- $\mathrm{R} \times$ Medical department & & $-0.10(0.227)$ & & \\
\hline \multicolumn{5}{|l|}{ Intra class correlation } \\
\hline ICC(\%)/design effect (hospital ward level) & $5.68 / 1.69$ & $2.46 / 1.30$ & $5.35 / 1.65$ & $8.64 / 2.05$ \\
\hline ICC $(\%) /$ design effect (hospital level) & $0.56 / 1.47$ & $0,72 / 1.61$ & $0.22 / 1.19$ & $0.74 / 1.62$ \\
\hline
\end{tabular}




\section{Strengths and limitations}

This study is based on data from one of the largest nurse surveys performed in Norway, and includes almost all Norwegian hospitals with more than 85 beds. Norwegian nurses give their workplaces better ratings of work environment and patient safety, and nurse-patient ratios are high compared with other countries. ${ }^{11}$ The good performance of Norwegian hospitals as assessed by nurses makes it of particular interest to study the organisational design.

Questions related to cross-sectional survey design are often addressed towards the inadequacy to prove causality. However, the intention of our study was not to add evidence of this kind, but to describe associations between nurses' perceptions of work environment and their assessments of patient safety and quality of nursing. We have not made statistical controls to mitigate the risk of common method bias as the value of this is questioned. ${ }^{4-51}$ The method for identifying the five-factor structure of NWI has been criticised, but is one of several ways to identify factor structure. ${ }^{52}$ The six-factor structure identified in the Norwegian data provided a nuanced description of work environment. Internal consistency was better for the sixfactor structure, and is probably better adapted to a Norwegian context. ${ }^{36} 38$ The questionnaires were distributed through the nurses' union representatives, and we have not been able to control whether loyalty to NNO has influenced the results. The age distribution of our sample is corresponding with studies from similar populations in Norway. ${ }^{53}$ The difference in age from nurses in the NNO member register may be explained by the exclusion of nurses in leader positions and part-time positions. Nurses' practice environments are complex and cannot be fully covered by a questionnaire, but overall the NWI is characterised as a 'promising instrument ${ }^{52}{ }^{54}$ However, NWI is developed to evaluate nurse-reported job outcomes, and the applicability of the instrument to patient safety might be uncertain. ${ }^{55}$ Statistics Norway and The Norwegian Directorate of Health are well-established registers with complete coverage. The high quality of their data collection has minimised the risk of inaccuracy of organisational structure variables and ensured the comparability between hospitals.

\section{Organisational process measures}

Educational level has been associated with risk-adjusted patient mortality and failure to rescue within 30 days of admission. ${ }^{56} 57$ Even though all Norwegian nurses hold a bachelor degree, we expected that education and career were associated with some of the outcome measures, but this was not the case. However, the association between quality system, involving issues as training for newly hired and continuity of nursing, and work-related and patientrelated outcomes indicate that integrated training programmes may be more important for patient safety and quality of nursing. ${ }^{57}$ The subscale quality system also represents continuous processes such as the presence of quality control programmes, systems for documentation and nursing versus medical orientation. These findings are supported in studies showing that quality programmes influence healthcare workers attitudes and increase improvement events. ${ }^{58-61}$ The existence of standards, infrastructure and quality systems contribute to expectations and predictability for the health professionals and maximise their efforts to avoid patient harm. ${ }^{1962}$

In our study Ward leadership was inconsistently associated with the outcomes. However, a positive association with patient safety management supports findings from studies that emphasise nurse leadership and a management that prioritises patient safety. ${ }^{10406364}$ In a recent study the authors found that engaged leadership strengthened both communication and teamwork and that these qualities of the organisation enhanced patient safety. ${ }^{65}$ Communication and collegial discussions are important aspects to streamline workflow and procedures to ensure patient safety, and serve as sources for professional development. ${ }^{6667}$ The association between good nurse-physician relation and high quality of care from other studies was supported in our findings. ${ }^{68-71}$ The channels for communicating results from performance measurements and other patient safety messages require engagement from leaders on all levels, and should probably be customised to the targeted healthcare profession.

Staff adequacy represents nurses' assessments of the possibility to get the work done, provide quality of care, and discuss problems related to care with colleagues. Processes that ensure adequate and targeted resource allocation may contribute to reduced length of stay, increase in ambulatory activity, as well as ensuring right competence at the right place and time. ${ }^{72} 73$ Associations between staff ratios and patient outcomes such as failure to rescue, unplanned extubation, cardiac arrest, nosocomial infections and risk-adjusted mortality have been found in several studies, indicating that staffing levels are related to quality and patient safety. ${ }^{15} 1921$ 74-77 Corresponding results have been shown in studies with nurse-reported outcome measures, but was not confirmed by our study. ${ }^{75-77}$ A possible reason for this is that nurse-patient ratios are high in Norway and that Norwegian nurses perceive work environment as better than nurses in other countries. ${ }^{11}$ This may indicate that passing a threshold for staff levels, challenges related to quality and patient safety could be met on an organisational level. ${ }^{11} 2378$

\section{Organisational structure measures}

Few organisational structure measures were significantly associated with outcome variables when hospital and hospital ward was introduced as levels in the analysis. Hence, when affiliation to regional university hospitals remained significant, it may as well be explained by a strong common perception of the hospital performance as of hospital type. Regional university hospital was not associated with nurse-reported patient-related outcomes implying that nurses' perception of quality and safety may be good 
despite the risk for complications among patients in these hospitals. Associations between hospital type and patient safety indicators are inconsistently reported by other authors that suggest that features other than hospital type are more important for patient outcomes. ${ }^{6} 7980$

The negative association between low frequency $\mathrm{AE}$ and local university hospital might confirm the assumption that common perception is a more decisive factor than hospital type. However, because of the small number of hospitals in this group, conditions in a single hospital might have influenced the results. Correlation on hospital and hospital ward levels were highest for low frequency $\mathrm{AE}$, indicating a stronger correlation for this outcome on these levels, and we cannot rule out that our findings are related to resources, patients' severity and nurses' perceptions of risk of complications. ${ }^{6}$ We found that nurses working in medical departments gave poorer ratings of patients' self-care ability and that medical department interacted with index for patient mix. We lack information about patients' severity and DRG-weights on departmental level, but the complexity in diseases and comorbidity among elderly patients may explain this result if the majority of them are admitted to medical departments. These considerations do not explain why being affiliated to a medical department was associated with nurse-reported patient safety, but may indicate that patient safety interventions are easier to apply and make visible in surgical departments as the procedures are more standardised. ${ }^{81}$

\section{Final remarks}

The agreement of respondents within organisational levels (ICCs) was in accordance with similar studies reviewed by Park and Lake. ${ }^{82}$ The culture of a group is formed by shared perceptions, thoughts and emotions, and the dependency of the observations at ward level may be explained by such phenomena. ${ }^{39}$

Organisational structure variables included in our study have minor impact on how nurses perceive workrelated and patient-related outcomes. However, the organisational process variables consistently related to all outcomes measures indicated that there is a considerable potential in addressing organisational design in improvement of patient safety and quality of care. This study makes a contribution to knowledge about how interventions should be targeted towards organisational processes in patient safety work. Further research should also address organisational processes relevant for other professions.

Acknowledgements The authors would like to thank all Norwegian nurses who responded on the nurse survey.

Contributors CT has been responsible for conception, design, analysis and interpretation of data, and has worked out the drafts and completion of the submitted version of the manuscript. All coauthors have revised the manuscript and substantially contributed with comments and ideas during the process, and given their final approval of the version submitted. ISS has contributed in data collection, development of conception and design of the study and interpretation of data. JH has contributed in development of design, analysis and interpretation of data. GB has contributed in development of conception and design of the study, and interpretation of data.

Funding Data were collected by Norwegian Nurses' Organisation and Norwegian Knowledge Centre for the Health Services in collaboration. CT was supported by a grant from Norwegian Nurses' Organisation.

\section{Competing interests None.}

Ethics approval The method of data collection and handling was approved by the Data Protection Official for Research

Provenance and peer review Not commissioned; externally peer reviewed.

Data sharing statement The data set is available at The Norwegian Knowledge Centre for the Health Services, and requests should be addressed by emailing cht@nokc.no.

\section{REFERENCES}

1. Committee on Quality of Health Care in America. Crossing the quality chasm: a new health system for the 21st century. Washington, DC: National Academy Press, 2001.

2. Wong J, Beglaryan $\mathrm{H}$. Strategies for hospitals to improve patient safety: a review of the research. The Change Foundation, 2004. Canada, Toronto.

3. Leape L, Berwick D, Clancy C, et al. Transforming healthcare: a safety imperative. Qual Saf Health Care 2009;18:424-8.

4. Hearld LR, Alexander JA, Fraser I, et al. Review: how do hospital organizational structure and processes affect quality of care? A critical review of research methods. Med Care Res Rev 2008;65:259-99.

5. Zohar D. Thirty years of safety climate research: reflections and future directions. Accid Anal Prev 2010;42:1517-22.

6. Rivard PE, Elixhauser A, Christiansen $\mathrm{CL}$, et al. Testing the association between patient safety indicators and hospital structural characteristics in VA and nonfederal hospitals. Med Care Res Rev 2010;67:321-41.

7. Battles JB, Lilford RJ. Organizing patient safety research to identify risks and hazards. Qual Saf Health Care 2003;12(Suppl 2):ii2-7.

8. Donabedian A. Selecting approaches to assessing performance. In: Donabedian A. An introduction to quality assurance in health care. New York: Oxford University Press, 2003.

9. Battles JB. Quality and safety by design. Qual Saf Health Care 2006;15(Suppl 1):i1-3.

10. Cummings $\mathrm{G}$. The call for leadership to influence patient outcomes Nurs Leadersh (Tor Ont) 2011;24:22-5.

11. Aiken LH, Sermeus W, Van den Heede K, et al. Patient safety, satisfaction, and quality of hospital care: cross sectional surveys of nurses and patients in 12 countries in Europe and the United States. BMJ 2012;344:e1717.

12. Wallace JE, Lemaire JB, Ghali WA. Physician wellness: a missing quality indicator. Lancet 2009;374:1714-21.

13. Hickam $\mathrm{DH}$, Severance $S$, Feldstein $A$, et al. The effect of health care working conditions on patient safety. Evid Rep Technol Assess (Summ) 2003;:1-3.

14. Grol R. Changing physicians' competence and performance: finding the balance between the individual and the organization. J Contin Educ Health Prof 2002;22:244-51.

15. Stone PW, Mooney-Kane C, Larson EL, et al. Nurse working conditions and patient safety outcomes. Med Care 2007;45:571-8.

16. Cummings GG, Midodzi WK, Wong CA, et al. The contribution of hospital nursing leadership styles to 30-day patient mortality. Nurs Res 2010;59:331-9.

17. Aiken LH, Clarke SP, Sloane DM, et al. Effects of hospital care environment on patient mortality and nurse outcomes. J Nurs Adm 2008;39(7-8 Suppl):S45-51.

18. Estabrooks CA, Midodzi WK, Cummings GG, et al. The impact of hospital nursing characteristics on 30-day mortality. Nurs Res 2005;54:74-84.

19. Needleman J, Buerhaus P, Pankratz VS, et al. Nurse staffing and inpatient hospital mortality. N Engl J Med 2011;364:1037-45.

20. Blegen MA, Goode CJ, Reed L. Nurse staffing and patient outcomes. Nurs Res 1998;47:43-50.

21. Kane RL, Shamliyan TA, Mueller C, et al. The association of registered nurse staffing levels and patient outcomes: systematic review and meta-analysis. Med Care 2007;45:1195-204.

22. Singer SJ, Gaba DM, Falwell A, et al. Patient safety climate in 92 US hospitals: differences by work area and discipline. Med Care 2009;47:23-31 
23. Carayon P, Schoofs HA, Karsh BT, et al. Work system design for patient safety: the SEIPS model. Qual Saf Health Care 2006;15 (Suppl 1):i50-8.

24. Westbrook MT, Braithwaite J, Travaglia JF, et al. Promoting safety: longer-term responses of three health professional groups to a safety improvement programme. Int J Health Care Qual Assur 2007;20:555-71.

25. Listyowardojo TA, Nap RE, Johnson A. Variations in hospital worker perceptions of safety culture. Int J Qual Health Care 2012;24:9-15.

26. Gallego B, Westbrook MT, Dunn AG, et al. Investigating patient safety culture across a health system: multilevel modelling of differences associated with service types and staff demographics. Int J Qual Health Care 2012;24:311-320.

27. Travaglia JF, Westbrook MT, Braithwaite J. Implementation of a patient safety incident management system as viewed by doctors, nurses and allied health professionals. Health (London) 2009;13:277-96.

28. McHugh MD, Stimpfel AW. Nurse reported quality of care: a measure of hospital quality. Res Nurs Health 2012;35:566-75.

29. Shang J, Friese CR, Wu E, et al. Nursing practice environment and outcomes for oncology nursing. Cancer Nurs 2012 Epub ahead of print 29 June 2012 doi:10.1097/NCC.0b013e31825e4293

30. Van BP, Clarke S, Roelant E, et al. Impacts of unit-level nurse practice environment and burnout on nurse-reported outcomes: a multilevel modelling approach. $J$ Clin Nurs 2010;19:1664-74.

31. Ausserhofer D, Schubert M, Desmedt M, et al. The association of patient safety climate and nurse-related organizational factors with selected patient outcomes: A cross-sectional survey. Int J Nurs Stud 2012,http://dx.doi.org/10.1016/j.ijnurstu.2012.04.007. Epub ahead of print.

32. Aiken LH, Clarke SP, Sloane DM, et al. Nurses' reports on hospital care in five countries. Health Aff (Millwood) 2001;20:43-53.

33. Aiken LH, Clarke SP, Sloane DM. Hospital staffing, organization, and quality of care: cross-national findings. Int $J$ Qual Health Care 2002;14:5-13.

34. Braithwaite J, Westbrook MT, Robinson M, et al. Improving patient safety: the comparative views of patient-safety specialists, workforce staff and managers. BMJ Qual Saf 2011;20:424-31.

35. Warren CR, Landis RS. One is the loneliest number: a meta-analytic investigation on single-item measure fidelity. Ergometrika 2007;4:32-5.

36. Lake ET. Development of the practice environment scale of the Nursing Work Index. Res Nurs Health 2002;25:176-88.

37. Blegen MA, Gearhart S, O'Brien R, et al. AHRQ's hospital survey on patient safety culture: psychometric analyses. J Patient Saf 2009;5:139-44.

38. Sjetne IS, Tvedt C, Squires A. Måleinstrumentet 'The Nursing Work Index-Revised'-oversettelse og utprøving av en norsk versjon. ('The Nursing Work Index-Revised'-Instrument translation and assessment of a Norwegian version). Sykepleien Forskning 2011;6:358-65.

39. Schein EH. Organizational culture and leadership. San Francisco: Jossey-Bass, 2004.

40. Wong CA, Cummings GG. The relationship between nursing leadership and patient outcomes: a systematic review. J Nurs Manag 2007;15:508-21.

41. Huseby B. (red). Specialist health care services 2009 (SAMDATA) Oslo: The Norwegian Directorate of Health, 2010, 978. Ref Type: Report

42. Statistics Norway. Statbank. 2012. http://statbank.ssb.no/ statistikkbanken (accessed 1 Dec 2009).

43. West E. Management matters: the link between hospital organisation and quality of patient care. Qual Health Care 2001;10:40-8.

44. Taylor SL, Dy S, Foy R, et al. What context features might be important determinants of the effectiveness of patient safety practice interventions? BMJ Qual Saf 2011;20:611-17.

45. Dy SM, Taylor SL, Carr LH, et al. A framework for classifying patient safety practices: results from an expert consensus process. BMJ Qual Saf 2011:20:618-24.

46. Kramer M, Schmalenberg C, Brewer BB, et al. Accurate assessment of clinical nurses' work environments: response rate needed. Res Nurs Health 2009;32:229-40.

47. Spector PE, Brannick MT. Common method issues: an introduction to the feature topic in organizational research methods. Organ Res Methods 2010;13:403-6.

48. Conway JM, Lance CE. What reviewers should expect from authors regarding common method bias in organizational research. $J$ Bus Psychol 2010;25:325-34.

49. Brannick MT, Chan D, Conway JM, et al. What is method variance and how can we cope with it? A panel discussion. Organ Res Methods 2010;13:407-20.
50. Lance CE, Dawson P, Birkelbach D, et al. Method effects, measurement error, and substantive conclusions. Organ Res Methods 2011;13:435-55.

51. Siemsen E, Roth A, Oliveira P. Common method bias in regression models with linear, quadratic, and interaction effects. Organ Res Methods 2010;13:456-76.

52. Cummings GG, Hayduk L, Estabrooks CA. Is the nursing work index measuring up?: moving beyond estimating reliability to testing validity. Nurs Res 2006;55:82-93.

53. Sjetne IS, Veenstra M, Ellefsen B, et al. Service quality in hospital wards with different nursing organization: nurses' ratings. J Adv Nurs 2009;65:325-36.

54. Bonneterre V, Liaudy S, Chatellier G, et al. Reliability, validity, and health issues arising from questionnaires used to measure Psychosocial and Organizational Work Factors (POWFs) among hospital nurses: a critical review. J Nurs Meas 2008;16:207-30.

55. Zohar D. Safety climate in industrial organizations: theoretical and applied implications. J Appl Psychol 1980;65:96-102.

56. Aiken LH, Clarke SP, Cheung RB, et al. Educational levels of hospital nurses and surgical patient mortality. JAMA 2003;290:1617-23.

57. McAlearney AS, Garman AN, Song PH, et al. High-performance work systems in health care management, part 2: qualitative evidence from five case studies. Health Care Manage Rev 2011;36:214-26.

58. Haley RW, Quade D, Freeman HE, et al. The SENIC Project. Study on the efficacy of nosocomial infection control (SENIC Project). Summary of study design. Am J Epidemiol 1980;111:472-85.

59. Naveh E, Stem Z. How quality improvement programs can affect general hospital performance. Int J Health Care Qual Assur Inc Leadersh Health Serv 2005;18:249-70.

60. Maguerez G, Erbault M, Terra JL, et al. Evaluation of 60 continuous quality improvement projects in French hospitals. Int $J$ Qual Health Care 2001;13:89-97.

61. Tvedt C, Bukholm G. Healthcare workers' self-reported effect of an interventional programme on knowledge and behaviour related to infection control. Qual Saf Health Care 2010;19:e7.

62. Kohn LT, Corrigan JM, Donaldson MSe. To err is human: building a safer health system. Washington, DC: National Academy Press, 2000.

63. Goeschel CA, Wachter RM, Pronovost PJ. Responsibility for quality improvement and patient safety: hospital board and medical staff leadership challenges. Chest 2010;138:171-8.

64. Conway J. Getting boards on board: engaging governing boards in quality and safety. Jt Comm J Qual Patient Saf 2008;34:214-20.

65. Castner J, Foltz-Ramos K, Schwartz DG, et al. A leadership challenge: staff nurse perceptions after an Organizational TeamSTEPPS Initiative. J Nurs Adm 2012;42:467-72.

66. Quick J. Modern perioperative teamwork: an opportunity for interprofessional learning. J Perioper Pract 2011;21:387-90.

67. West $P$, Sculli G, Fore $A$, et al. Improving patient safety and optimizing nursing teamwork using crew resource management techniques. J Nurs Adm 2012;42:15-20.

68. Manser T. Teamwork and patient safety in dynamic domains of healthcare: a review of the literature. Acta Anaesthesiol Scand 2009;53:143-51.

69. Auerbach AD, Sehgal NL, Blegen MA, et al. Effects of a multicentre teamwork and communication programme on patient outcomes: results from the Triad for Optimal Patient Safety (TOPS) project. BMJ Qual Saf 2011:21:118-26.

70. Baker DP, Day R, Salas E. Teamwork as an essential component of high-reliability organizations. Health Serv Res 2006;41 (4 Pt 2):1576-98

71. Schmalenberg C, Kramer M. Nurse-physician relationships in hospitals: 20,000 nurses tell their story. Crit Care Nurse 2009:29:74-83.

72. Christianson MK, Sutcliffe KM, Miller MA, et al. Becoming a high reliability organization. Crit Care 2011;15:314.

73. Allen D, Rixson L. How has the impact of 'care pathway technologies' on service integration in stroke care been measured and what is the strength of the evidence to support their effectiveness in this respect? Int J Evid Based Healthc 2008;6:78-110.

74. Pronovost P, Needham D, Berenholtz S, et al. An intervention to decrease catheter-related bloodstream infections in the ICU. $N$ Engl J Med 2006;355:2725-32.

75. Tervo-Heikkinen T, Kiviniemi V, Partanen P, et al. Nurse staffing levels and nursing outcomes: a Bayesian analysis of Finnish-registered nurse survey data. J Nurs Manag 2009;17:986-93. 
76. Djukic M, Kovner CT, Brewer CS, et al. Work environment factors other than staffing associated with nurses' ratings of patient care quality. Nurs Adm 2012;42(10 Suppl): S17-26.

77. Gunnarsdottir S, Clarke SP, Rafferty AM, et al. Front-line management, staffing and nurse-doctor relationships as predictors of nurse and patient outcomes. A survey of Icelandic hospital nurses. Int J Nurs Stud 2007;46:920-7.

78. Shekelle PG, Pronovost PJ, Wachter RM, et al. Advancing the science of patient safety. Ann Intern Med 2011;154:693-6.
79. Thornlow DK, Stukenborg GJ. The association between hospital characteristics and rates of preventable complications and adverse events. Med Care 2006;44:265-9.

80. Sjetne IS, Veenstra M, Stavem K. The effect of hospital size and teaching status on patient experiences with hospital care: a multilevel analysis. Med Care 2007;45:252-8.

81. El-Jardali F, Dimassi H, Jamal D, et al. Predictors and outcomes of patient safety culture in hospitals. BMC Health Serv Res 2011;11:45.

82. Park S, Lake ET. Multilevel modeling of a clustered continuous outcome: nurses' work hours and burnout. Nurs Res 2005;54:406-13. 